\title{
Load Frequency Control for multiarea Power System using Secondary Controllers
}

\author{
Nagendra Kumar,"* and Akhilesh Singh ${ }^{2}$ \\ ${ }^{I}$ Department of Electrical and Electronics Engineering, G. L. Bajaj Institute of Technology \& \\ Management, Greater Noida 201306, India \\ ${ }^{2}$ Department of Electrical Engineering, Seemant Institute of Technology Pithoragarh, \\ Uttrakhand 262501, India
}

('Corresponding author's e-mail: Nagendra.kumar@glbitm.ac.in)

Received: 3 March 2021, Revised: 3 June 2021, Accepted: 20 June 2021

\begin{abstract}
Load frequency control (LFC) is essential for the stable operation of a power system network. The principal task of LFC is to manage the output of the generator with respect to change in the network frequency and tie-line power; such as to restore the scheduled frequency and power exchange with other areas in a prescribe bounds. This paper carries out an analysis of the LFC for 2 areas reheat thermal system and 4 areas thermal reheat system using a generation rate constraint (GRC), by comparison of performances of secondary controllers like model predictive control (MPC), proportional integral derivative (PID), and Fuzzy cascaded PID as load frequency control scheme. A well-known optimization algorithm, i.e., Big Bang Big Crunch (BBBC) is used to obtain optimal gains of PID controllers. Various load perturbations in different areas have been considered to check the response of the controllers. Comparative analysis of the results has been obtained in terms of overshoot, undershoot and settling time. It is seen that in all cases, apart from some peaky oscillation in responses, MPC performs better than other controllers, specifically in terms of settling time. The robustness of the MPC controller is also more evident than the other controllers.
\end{abstract}

Keywords: Automatic Control Error (ACE), Fuzzy logic control (FLC), Load frequency control (LFC), Model predictive control (MPC), Proportional-integral-derivative (PID)

\section{Introduction}

The power system is one of the most complex engineering systems which serves as the back bone for the growth and development of any nation. For the successful working of the power system, a balance between power generation and load demand is required all the time, since the mismatch between these 2 can lead to severe conditions. After any unbalance between generation and load requirements, load frequency control (LFC) is accountable for frequency control in power systems. The purpose of the LFC is to preserve the scheduled frequency and tie-line power in normal conditions. The LFC is used in 2 stages or loops in power systems: Primary control and secondary control [1]. The arrangement that takes care of the secondary frequency control in an electrical system is known as automatic generation control (AGC). It keeps the generation-load of an area in a specified limit and takes care of any unbalance in frequency and power exchange on occurrence of load change [1,2]. Since power system is a vast network therefore, to have a better control it is divided into control areas. One control area is connected to another using a tie-line to exchange power and to support one another in the case of emergency conditions $[3,4]$. In case of an interconnected power system, any small sudden load change in any of the areas causes the fluctuation of the frequencies of each and every area and also there is fluctuation of power in tie line. So, a LFC scheme basically incorporates an appropriate control system for an interconnected power system. Time delay plays an important role in better supervision and control of various parameters related to LFC [5]. It is seen from literature survey that power system performance depends on control structure and fitness function. Therefore, it is always welcome to propose and apply new high performance optimization algorithms to real-world issues. In LFC, to maintain equilibrium, the controller plays an important role. Therefore, many methods have been used in literature, such as classical, adaptive, optimal, nonlinear, modern, etc. Additionally, control systems are also used to implement LFC controllers based 
on various soft computing methods such as RL, GA, PSO, HS, and many more [6-9]. A conventional system comprising thermal/hydro or a mixture of both, has been studied in the past. I, PI and PID [10] are popular among researchers due to their merits, like simple construction, easy implementation, good performance, etc. The effectiveness of these control approaches have successfully been seen in many areas from power system to other system. However, it has been shown that conventional techniques are definitely not preferred when the number of parameters to be optimized is high. However, the stability of the power system is a point of prime concern. This increases the role and responsibility of the control approaches that are being used in power systems [11-13]. The use of conventional controllers has some demerits, such as that they are very slow in operation, they do not care about the inherent nonlinearities of different power system components, it is very hard to decide the gain of the integrator setting according to changes in the operating point. Advance control system has a lot of advantage over conventional integral controller. They are much faster than integral controllers and also they give better stability response than integral controllers. The changed environment requires other control schemes like the adaptive neuro fuzzy inference system (ANFIS), NARMA-L2 controller, etc [14,15]. Zadeh presented the theory of fuzzy sets and Mamdani implemented the $1^{\text {st }}$ fuzzy logic control algorithm on a steam engine $[16,17]$. Fuzzy logic controller performance is based on the experience and knowledge of a human operator. MPC predicts the future output of the system and produces optimal control. It has also found its application in the frequency control of power systems composed of wind turbines, SMES, and the DC grid [18-21]. Since different control approaches have their merits and limitations, therefore, in this study authors have carried out a comparison of performances of the approaches i.e., PID, Fuzzy cascaded PID and MPC on a 2 area and 4 area reheat thermal power system in a deregulated environment.

\section{Systems for LFC}

Whenever a load imbalance occurs, the speed of the prime mover changes to compensate for that effect. The frequency also gets affected from that load imbalance. That change in speed is controlled by the governor of the generators. Once the speed change eliminates, the governor speed is made constant. Due to the varying nature of load governor speed is also not to a set point, therefore, secondary control mechanism with integrator is used to remove offset and bring the system to its normal value called reset point. Two and 4 area thermal power systems have been considered as test systems to check the performance of the designed controllers. The block diagram representation of 2 area power system is shown in Figure 1. Figure 2 shows block diagram of 4 area power system. Any unbalance between power generation and load gives rise to an area control error (ACE). A controller is used to eliminate ACE given in Eq. (1).

$$
\mathrm{ACE}_{\mathrm{i}}=\mathrm{B}_{\mathrm{i}} \Delta \mathrm{F}_{\mathrm{i}}+\Delta \mathrm{Ptie}_{\mathrm{i}}
$$

\section{Control approaches}

Secondary control approach plays an important role in LFC to bring frequency and tie-line power back to normal. Many approaches have been used in the past, but in this work, 4 controllers, namely PID, Fuzzy cascaded PID and MPC have been designed and tested for the system given in Figures $\mathbf{1}$ and 2 respectively.

\section{PID control scheme}

PID is a simple and easy to implement control scheme that is being used regularly in many applications. The PID controller can be represented as follows:

$$
\mathrm{G}_{\mathrm{PID}}(\mathrm{s})=\mathrm{K}_{\mathrm{P}}+\mathrm{K}_{\mathrm{I}} / \mathrm{s}+\mathrm{K}_{\mathrm{D}} \mathrm{s}
$$

Where, $\mathrm{K}_{\mathrm{P}}, \mathrm{K}_{\mathrm{I}}$, and $\mathrm{K}_{\mathrm{D}}=$ PID parameters, for effective performance of PID, its parameters should be obtained optimally. Therefore, in this work, the BBBC algorithm is used to decide parameters by minimizing the fitness function, given in Eq. (3).

$$
\mathrm{F}=\frac{1}{\mathrm{~m}} \sum_{\mathrm{i}=1}^{\mathrm{m}}\left[\left(\mathrm{ACE}_{\mathrm{i}}\right)^{2}\right]=\frac{1}{\mathrm{~m}} \sum_{\mathrm{i}=1}^{\mathrm{m}}\left[\left(\mathrm{B}_{\mathrm{i}} \Delta \mathrm{f}_{\mathrm{i}}+\Delta \mathrm{Ptie}_{\mathrm{i} \text {-error }}\right)^{2}\right]
$$


One PID controller has been taken in each control area.

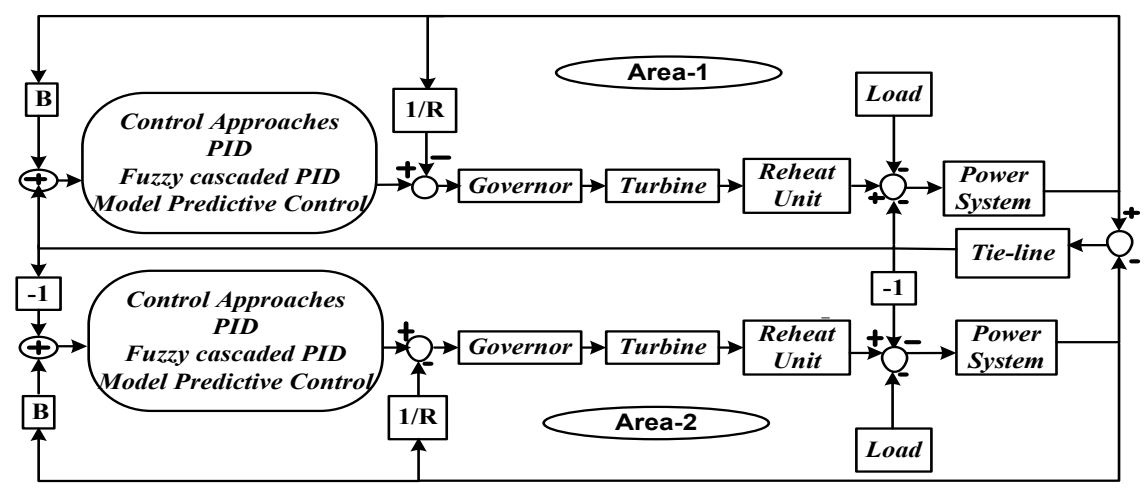

Figure 1 Block diagram of 2 area power system.

The steps determining parameters of PID using BBBC are as follows:

Step 1: The population is generated for controller,

$$
\mathrm{X}_{\mathrm{ij}}{ }^{(\mathrm{k})}=\mathrm{X}_{\mathrm{i}(\min )}{ }^{(\mathrm{k})}+\operatorname{rand} \cdot\left(\mathrm{X}_{\mathrm{i}(\max )}{ }^{(\mathrm{k})}-\mathrm{X}_{\mathrm{i}(\min )}{ }^{(\mathrm{k})}\right)
$$

where $x=\left[K_{p}, K_{1}, K_{D}\right], k=$ total areas, $i=$ parameters, $j=$ population size.

Step 2: For each population fitness function (3) is evaluated.

Step 3: Center of mass given in Eq. (5) is calculated here.

$$
X_{c o m}=\frac{\sum_{j=1}^{p} \frac{X_{i j}{ }^{(k)}}{F_{j}}}{\sum_{j=1}^{p} \frac{1}{F_{j}}}
$$




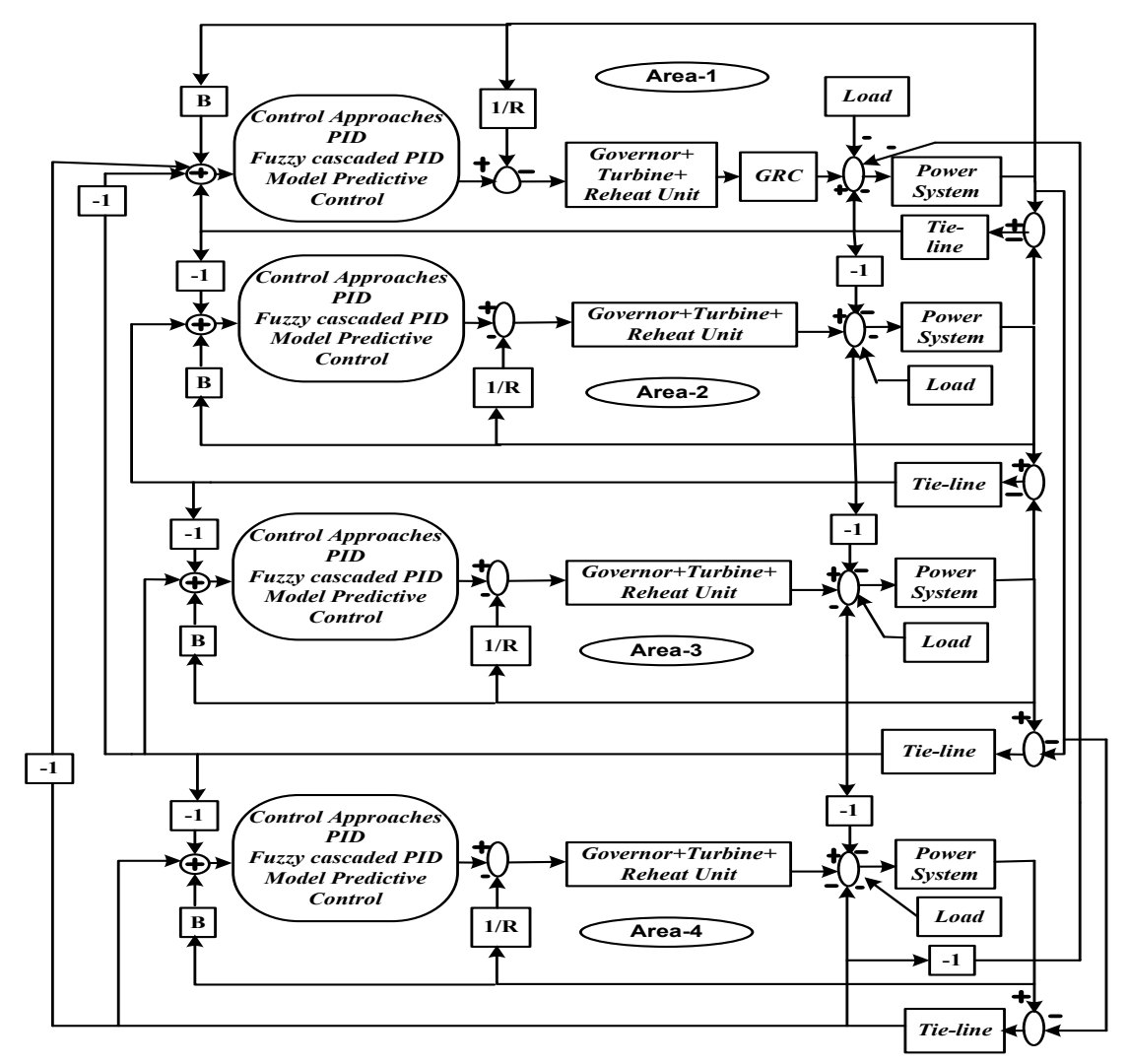

Figure 2 Block diagram of 4 area power system.

Step 4: New population generated around $X_{\text {com }}$.

$\mathrm{X}_{\mathrm{ij}(\text { new })}{ }^{\mathrm{k}}=\mathrm{X}_{\text {com }}+\frac{\mathrm{r} \cdot \alpha\left(\mathrm{x}^{\mathrm{k}}{ }_{\mathrm{i}(\max )}-\mathrm{x}^{\mathrm{k}}{ }_{\mathrm{i}(\min )}\right)}{\mathrm{K}}$

where $\alpha=$ limiting parameter, $\mathrm{r}=$ random number, $\mathrm{K}=$ iteration

Step 5: In this step, next parameters are generated.

$\mathrm{x}_{\mathrm{ij} \text { (next) }}{ }^{\mathrm{k}}={ }_{\min }\left\{\mathrm{F}\left(\mathrm{x}_{\mathrm{ij} \text { (previous) }}^{\mathrm{k}}\right), \mathrm{F}\left(\mathrm{x}_{\mathrm{ij} \text { (new) }}^{\mathrm{k}}\right)\right\}$

Step 6: It is the step where error is calculated and if it is less than the specified one, algorithm stop. A 30-population, 3-variables, and 10-parameter limiting size have been used as BBBC parameters to obtain optimal PID control scheme. The optimal parameters of the designed parameters are $\mathrm{K}_{\mathrm{P}}=-11.04$, $\mathrm{K}_{\mathrm{I}}=-2.558$ and $\mathrm{K}_{\mathrm{D}}=-11.878$.

Fuzzy logic cascaded PID control approach

The Fuzzy logic controller is centered on fuzzy logic and offers a procedure which converts an expert knowledge-based linguistic strategy into an automatic control strategy. Figure 3 shows the various components of fuzzy control, i.e., deffuzification, knowledge base, fuzzy interface, fuzzification. In this paper, 7 functions of triangular type membership are taken for each input, which is shown in Figure 4 below. In Figure 5, the surface diagram of both the input and output is given. 


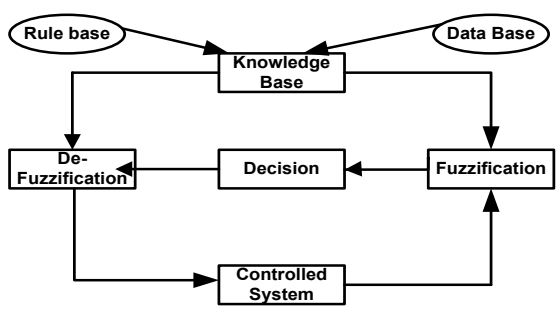

Figure 3 Block diagram representation of fuzzy control scheme.

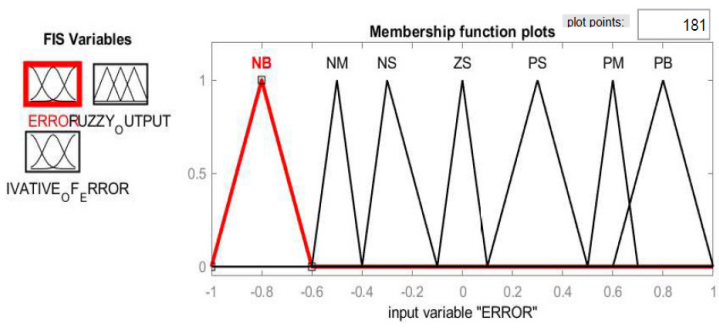

Figure 4 Membership functions for load frequency control.

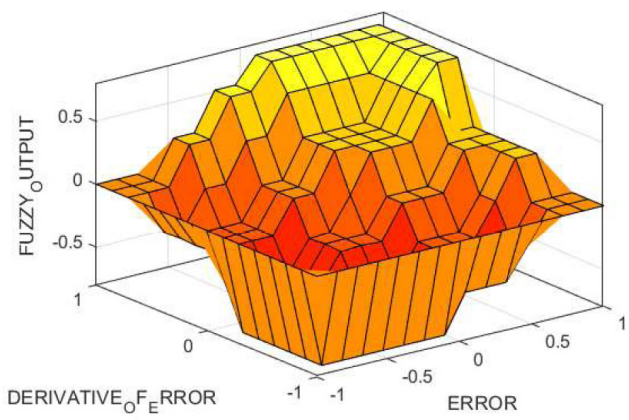

Figure 5 Surface diagram of input and output.

A total of 49 fuzzy rules were adopted for the input-output relationship based on the 7 membership function, where NB is (-ve large), NM is (-ve medium), NS is (-ve small), Z is (Zero), PS is (+ small), $\mathrm{PM}$ is $(+$ medium $), \mathrm{PB}$ is $(+\mathrm{Big})$, as given in Table 1.

Table 1 Rule base for LFC.

\begin{tabular}{cccccccc}
\hline \multirow{2}{*}{ Area Control Error } & \multicolumn{7}{c}{ Derivative of area control error } \\
\cline { 2 - 7 } & NB & NM & NS & Z & PS & PM & PB \\
\hline NB & NB & NB & NM & NB & ZS & NS & NM \\
NM & NB & NB & NB & NM & PM & ZS & NS \\
NS & NB & NB & NM & NS & PM & PB & ZS \\
Z & NB & NM & NS & ZS & PS & PM & PB \\
PS & NM & NS & ZS & PB & PS & PS & PM \\
PM & NS & ZS & PS & PM & PS & PS & PS \\
PB & ZS & PM & PM & PS & PS & PS & PS \\
\hline
\end{tabular}

In this work, for the Fuzzy cascaded PID control scheme given in Figure 6, ACE and derivation of area control error (dACE) have been taken as an input to the fuzzy control scheme and the output of this scheme has been compared with the deviation in frequency. The error works as an input to the PID control to obtain the optimal output. The detail explanation on fuzzy control can be referred from $[19,20]$. 


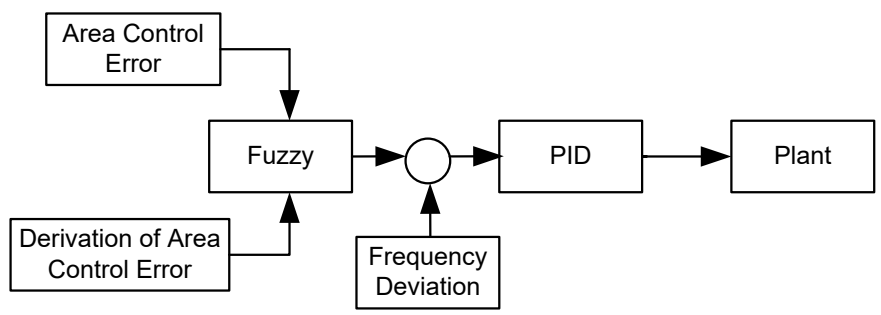

Figure 6 Block diagram of Fuzzy cascaded PID.

\section{Model predictive control}

MPC control scheme has been used as a satisfactory control application in industries because of easy computation, real time implementations, incorporation of delays and handling of constraint abilities [21]. Figure 7 shows the structure of the MPC used in this study. MPC predicts the system's future output on the basis of past-present I/O and future control actions. Free and forced responses are 2 main components of the forecast and are required for the overall forecast. Further, the optimizer calculates the best future control by minimizing a cost function given in Eq. (16) subjected to constraints given in Eq. (9), means the MPC minimizes the error in prediction with minimum control.

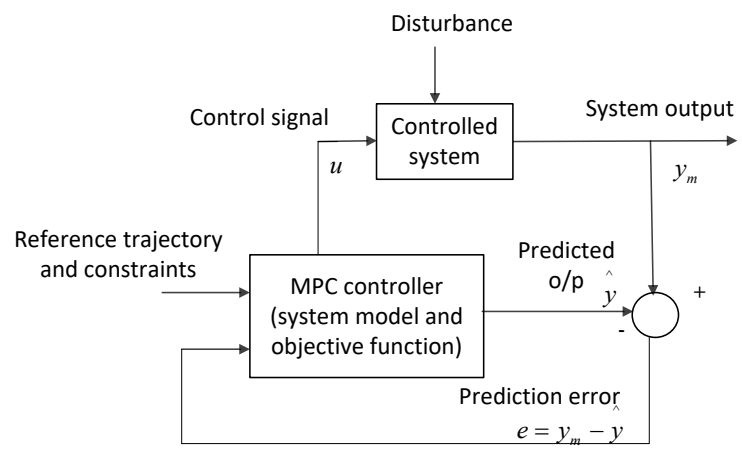

Figure 7 Simple structure of MPC scheme.

The objective function that is optimized by MPC is given as:

$$
J\left(L_{1}, L_{2}, N_{u}\right)=\sum_{j=L_{1}}^{L_{2}} \alpha(j)[y(\mathrm{k}+\mathrm{j} \mid \hat{\mathrm{k}}) \hat{-\mathrm{w}}(\mathrm{k}+\mathrm{j})]^{2}+\sum_{j=1}^{N_{u}} \beta(j)[k+j-1]^{2}
$$

where, $\mathrm{L}_{1}-\mathrm{L}_{2}$ are lower and upper prediction horizons, $\mathrm{N}_{\mathrm{u}}$ is the control horizon, $\alpha(j)-\beta(j)$ are weighting factors. $w(k+j)$ is the trajectory over the future horizon. $\Delta u(k+j)=0$ forl $\geq N_{u}$ is the relation used to give the number of future control. The control and output constraints are given in Eq. (9). The detailed explanation of MPC scheme can be referred from [21].

$$
\begin{aligned}
& u_{\text {min }} \leq \Delta u(k) \leq u_{\text {max }} \\
& y_{\text {min }} \leq \Delta y(k) \leq y_{\text {max }}
\end{aligned}
$$

\section{Results and discussion}

The above approaches have been designed for 2 and 4 area LFC schemes based on Figures 1 and 2.

Case (2 areas): Step load in areas 1 - 2

In this case, a step load of $1-1.2$ pu has been considered in both areas. The frequency of area-1 and area-2 on a load perturbation deviates from its nominal value, as shown in Figure 8. To bring back the frequency to its scheduled value, LFC initiates change in generation. It is apparent that area-1 and area-2 
frequency differences undergo oscillations with all controllers. However, both areas deviation quickly disappears with MPC control scheme. The change in generation, tie-line flow and ACE are shown in Figures 9 - 11, respectively.
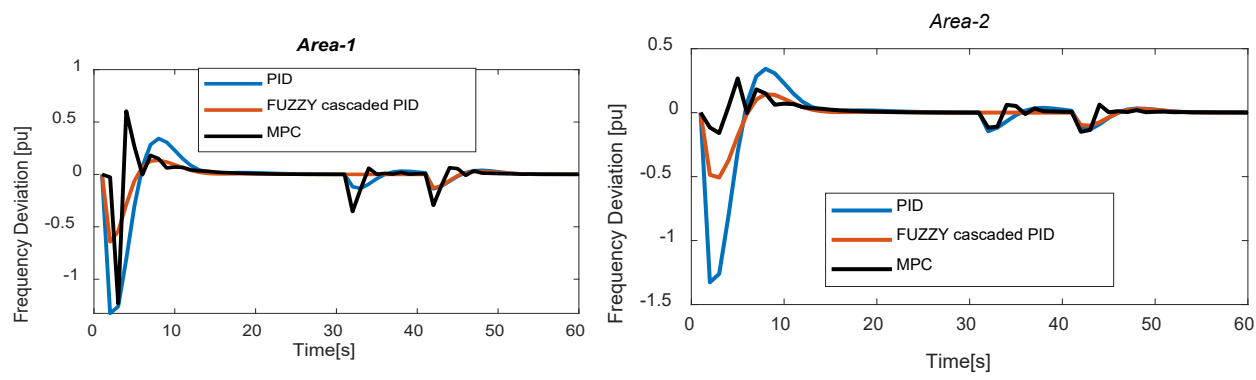

Figure 8 Frequency deviation in both areas.
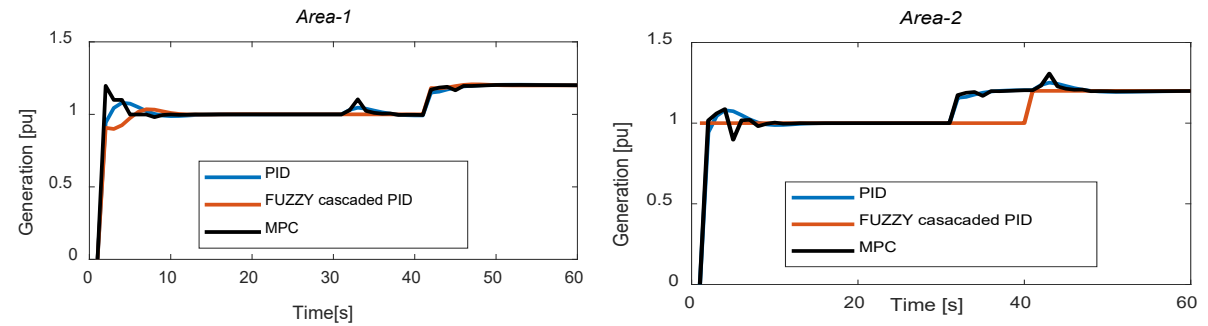

Figure 9 Change in generation in both areas.

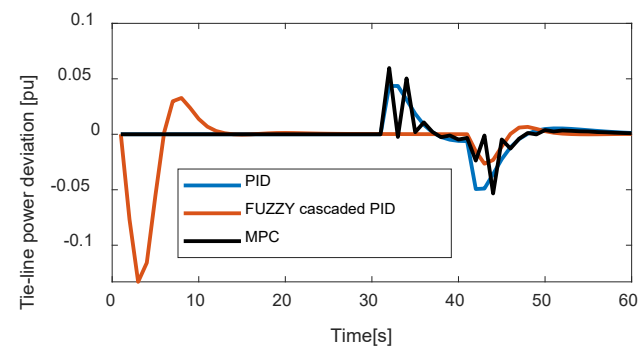

Figure 10 Tie-line power flow.
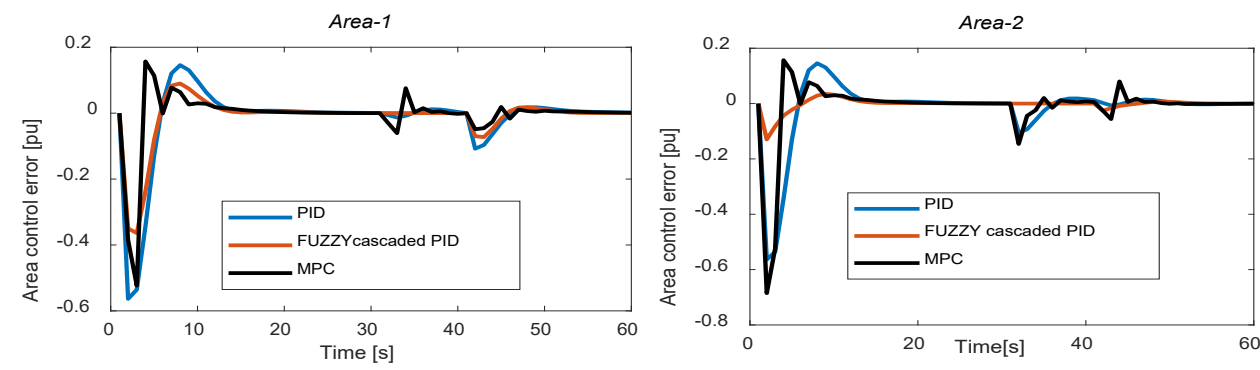

Figure $11 \mathrm{ACE}$ in both areas.

It is seen from results that the Gencos of each area changes its generation and settle down at the required value. Frequency deviation, tie-line power deviations and ACE signal converge to their final values more rapidly and attain steady state in a smaller time with MPC controller than other controllers. From these results, it is also observed that after a load perturbation, the required power to compensate for 
deviations to bring back frequency and ACE to nominal values in minimum settling time with smaller oscillations is provided by MPC, while with others, the power system encounters low damping and high magnitude oscillation and larger settling time characteristics.

\section{Case ( 4 areas): Step load in areas 1 - 4}

In this case, a step load of $1-1.3$ pu has been considered in areas $1-2$ and a step load of $1-1.2 \mathrm{pu}$ has been taken in areas $3-4$ respectively. The frequency of all 4 areas on a load perturbation deviates from its nominal value as shown in Figure 12. To bring back frequency to its scheduled value LFC initiates change in generation. The change in the generation, tie-line flow and ACE is shown in Figures 13 - 15 respectively.
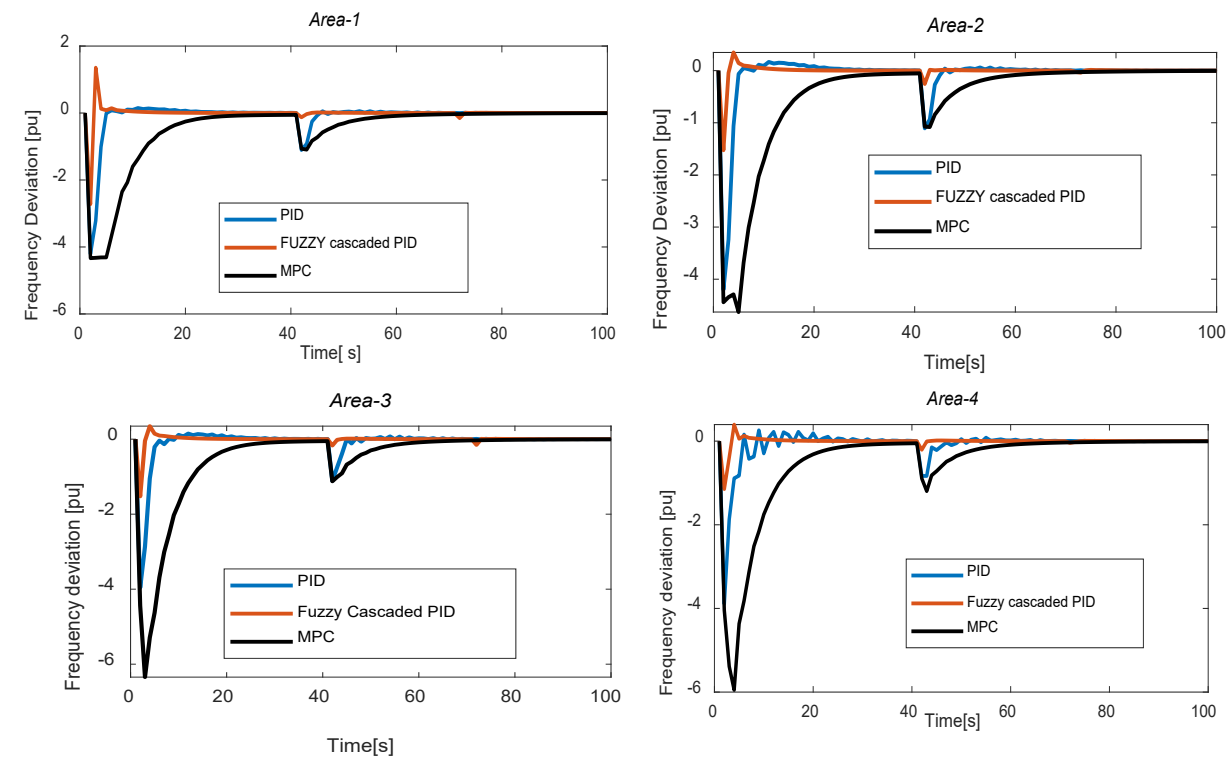

Figure 12 Frequency deviation in all 4 areas.
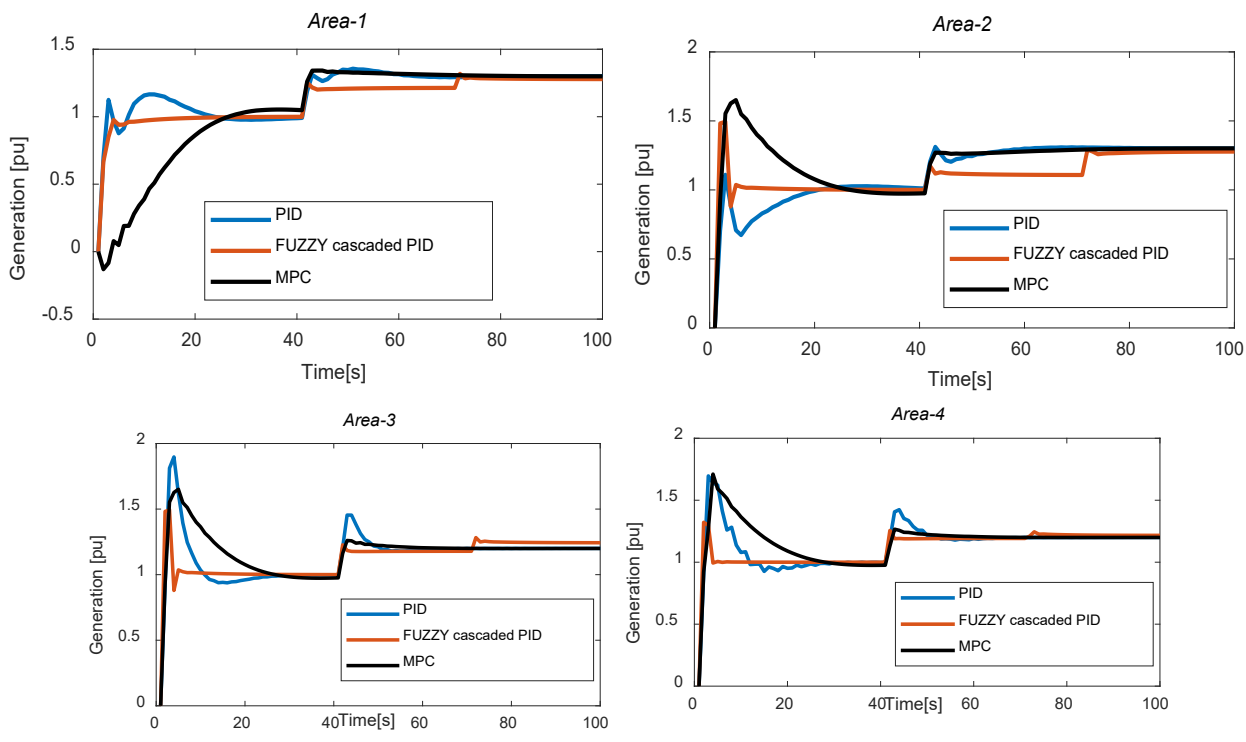

Figure 13 Change in generation in all 4 areas. 

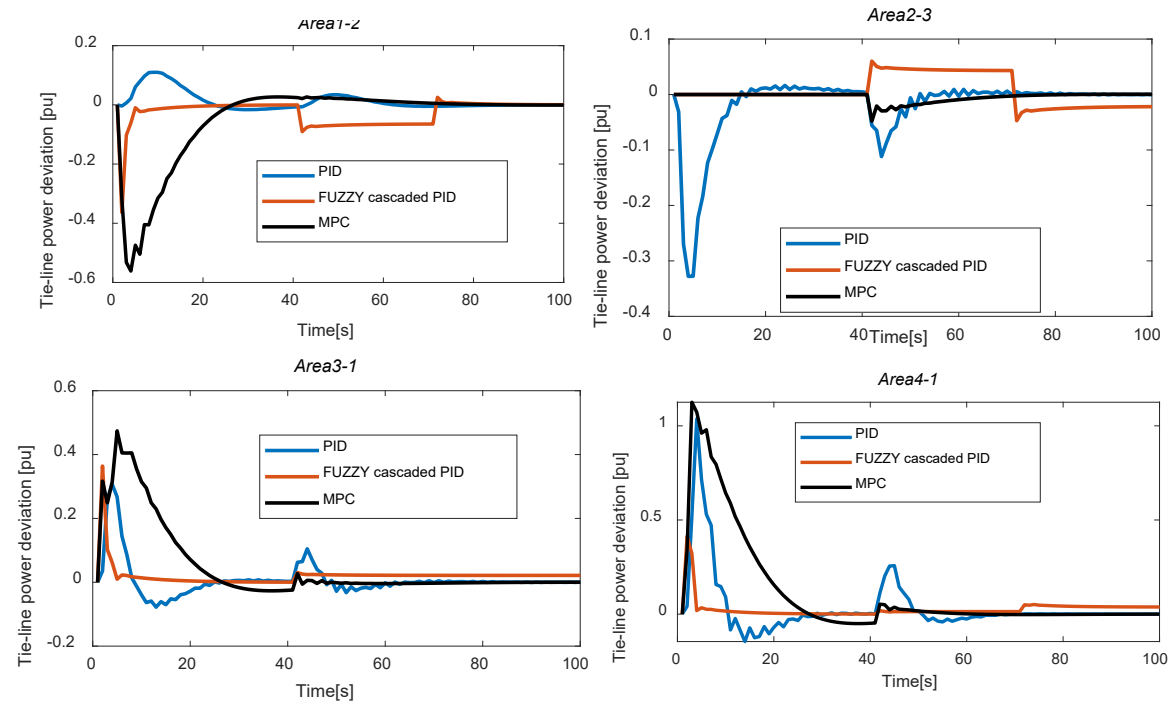

Figure 14 Tie-line power flow.
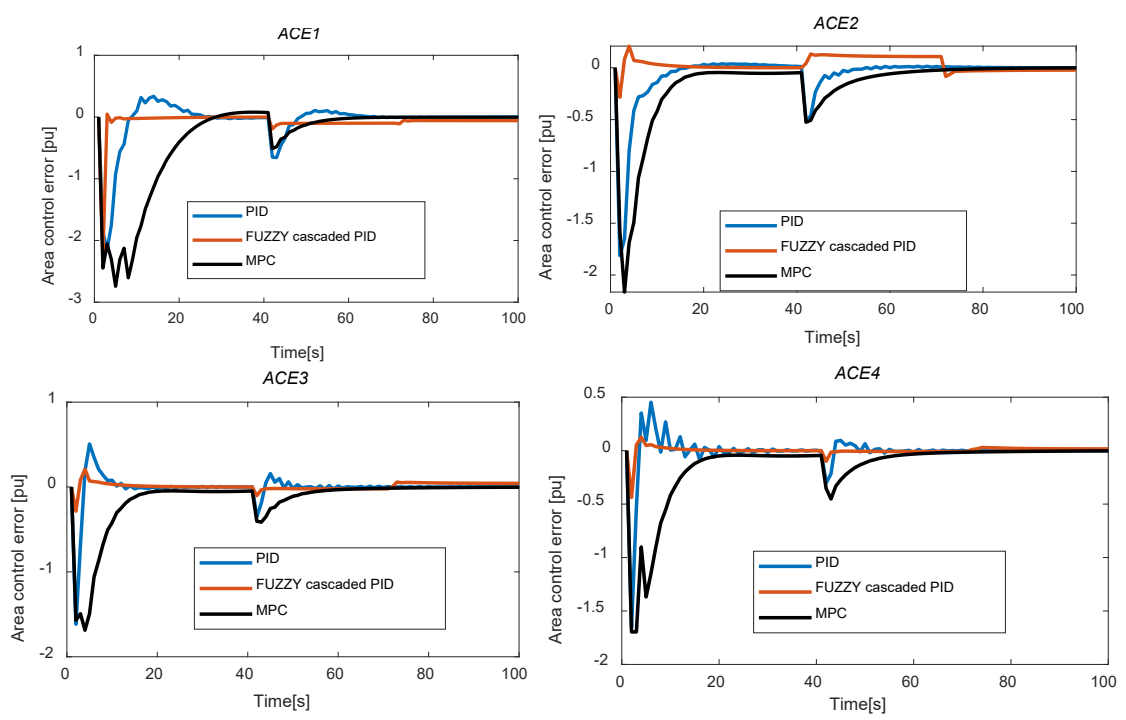

Figure 15 ACE.

It is seen that the generation of each area, deviation in frequency, tie-line power and ACE settled down to their desired value quickly with the MPC control scheme. MPC controller settles down the frequency deviations more quickly and smoothly in all areas than other controllers. Tables $\mathbf{2}$ and $\mathbf{3}$ present comparative results in terms of time domain parameters such as overshoot, undershoot, and settling time for 2 and 4 area power systems, respectively. It is revealed that Gencos with MPC controller takes smaller settling time to provide the desired generation than others. The results also show that the MPC controller is effective at reducing deviations to the desired value in a steady state. MPC gives desirable, reliable operation under all operating conditions and shows better performance than others. 
Table 2 Comparative performance analysis of all control schemes ( 2 areas power system).

\begin{tabular}{ccccc}
\hline Controller Type & Signal & Overshoot & Undershoot & Settling time (s) \\
\hline PID & $\Delta \mathrm{f}_{1}$ & 0.15 & -4.225 & 90 \\
& $\Delta \mathrm{f}_{2}$ & 0.06 & -4.235 & 85 \\
& $\Delta \mathrm{f}_{3}$ & 0.15 & -1.623 & 75 \\
& $\Delta \mathrm{f}_{4}$ & 0.16 & -1.128 & 85 \\
& $\Delta$ Ptie $_{1-2} / \Delta$ Ptie $_{2-3} /$ & $0.1 / 0.01 /$ & $0.0 /-0.33 /$ & $85 / 85 /$ \\
MPC & $\Delta$ Ptie $_{3-1} / \Delta \mathrm{Ptie}_{4-1} /$ & $0.32 / 1.11$ & $-0.09 /-0.1$ & $85 / 70$ \\
& $\Delta \mathrm{f}_{1}$ & 0.0 & -4.345 & 80 \\
& $\Delta \mathrm{f}_{2}$ & 0.0 & -4.625 & 75 \\
& $\Delta \mathrm{f}_{3}$ & 0.0 & -6.352 & 80 \\
Fuzzy Cascaded PID & $\Delta \mathrm{f}_{4}$ & 0.0 & -5.989 & 80 \\
& $\Delta$ Ptie $_{1-2} / \Delta \mathrm{Ptie}_{2-3} /$ & $0.01 / 0.0 /$ & $-0.589 /-0.05 /$ & $80 / 80 /$ \\
& $\Delta$ Ptie $_{3-1} / \Delta \mathrm{Ptie}_{4-1} /$ & $0.48 / 1.12$ & $-0.03 /-0.05$ & $70 / 65$ \\
& $\Delta \mathrm{f}_{1}$ & 1.432 & -2.753 & 88 \\
& $\Delta \mathrm{f}_{2}$ & 0.358 & -1.534 & 85 \\
& $\Delta \mathrm{f}_{3}$ & 0.328 & -3.956 & 75 \\
& $\Delta \mathrm{f}_{4}$ & 0.4 & -3.956 & 85 \\
& $\Delta \mathrm{Ptie}_{1-2} / \Delta \mathrm{Ptie}_{2-3} /$ & $0.02 / 0.05 /$ & $-0.389 /-1.86 /$ & $85 / 100^{+} /$ \\
& $\Delta \mathrm{Ptie}_{3-1} / \Delta \mathrm{Ptie}_{4-1} /$ & $0.38 / 0.4$ & $0.0 / 0.0$ & $100^{+/} 100^{+}$ \\
\hline
\end{tabular}

Table 3 Comparative performance analysis of all control schemes (4 areas power system).

\begin{tabular}{ccccc}
\hline Controller Type & Signal & Overshoot & Undershoot & Settling time (s) \\
\hline PID & $\Delta \mathrm{f}_{1}$ & 0.3429 & -1.3260 & 53 \\
& $\Delta \mathrm{f}_{2}$ & 0.3429 & -1.3260 & 55 \\
MPC & $\Delta \mathrm{Ptie}$ & 0.049 & -0.05 & 58 \\
& $\Delta \mathrm{f}_{1}$ & 0.6046 & -1.2313 & 48 \\
& $\Delta \mathrm{f}_{2}$ & 0.2678 & -0.1593 & 48 \\
Fuzzy Cascaded PID & $\Delta \mathrm{Ptie}$ & 0.05 & -0.055 & 50 \\
& $\Delta \mathrm{f}_{1}$ & 0.1349 & -0.6433 & 52 \\
& $\Delta \mathrm{f}_{2}$ & 0.1449 & -0.5074 & 55 \\
& $\Delta \mathrm{Ptie}$ & 0.03 & -0.1332 & 58 \\
\hline
\end{tabular}

\section{Conclusions}

The study of frequency deviation in 2 and 4 area thermal interconnected power systems with different (4) control schemes has been carried out in this paper. A variety of load change has been considered. At first a step load change in areas $1-2$ of 2 area power system has been considered. Second case is a step load perturbation in areas 1 - 4 of 4 areas has been considered. Authors have designed PID, Fuzzy PID and MPC control approaches for the above considered cases. The minimization of ACE has been chosen as an objective function to design PID control. BBBC method has been used to obtain optimum controller parameters. ACE and dACE have been considered as an input to design Fuzzy control scheme. MPC control approach has also been designed utilizing prediction and control model of 2 area power system. In time-domain simulations, the output of each controller is analysed by the dynamic behaviour of frequency, generation, tie-line power and ACE. Comparisons between the results obtained using all approaches are also shown in Tables $\mathbf{2}$ and $\mathbf{3}$ respectively. It is evident from the comparison that, apart from few instances of increased magnitude in oscillations, the MPC based control scheme provides better time-domain characteristics in terms of (overshoot/undershoot and settling time) and can be an effective choice as an AGC/LFC control scheme. 


\section{References}

[1] KS Rajesh and SS Dash. Load frequency control of autonomous power system using adaptive fuzzy based PID controller optimized on improved sine cosine algorithm. J. Ambient Intell. Humaniz. Comput. 2019; 10, 2361-73.

[2] M Farahani, S Ganjefar and M Alizadeh. PID controller adjustment using chaotic optimisation algorithm for multi-area load frequency control. IET Control Theory Appl. 2012; 6, 1984-92.

[3] A Khodabakhshia, ME Pour and R Hooshmand. Design of a robust load frequency control using sequential quadratic programming technique. Int. J. Electr. Power Energy Syst. 2012; 40, 1-8.

[4] DK Sambariya and R Prasad. Design of harmony search algorithm based tuned fuzzy logic power system stabilizer. Int. Rev. Electr. Eng. 2013; 8, 1594-607.

[5] KS Xiahou, Y Liu and QH Wu. Robust load frequency control of power systems against random time-delay attacks. IEEE Trans. Smart Grid 2021; 12, 909-11.

[6] Z Yan and Y Xu. Data-driven load frequency control for stochastic power systems: A deep reinforcement learning method with continuous action search. IEEE Trans. Power Syst. 2019; 34, 1653-6.

[7] H Gozde and MC Taplamacioglu. Automatic generation control application with craziness based particle swarm optimization in a thermal power system. Int. J. Electr. Power Energy Syst. 2011; 33, 8-16.

[8] SK Aditya and D Das. Design of load frequency controllers using genetic algorithm for two area interconnected hydropower system. Electr. Power Compon. Syst. 2003; 31, 81-94.

[9] ZW Geem, JH Kim and GV Loganathan. A new heuristic optimization algorithm: Harmony search. Simulation 2001; 76, 60-8.

[10] W Tan. Tuning of PID load frequency controller for power systems. Energy Convers. Manag. 2009; 50, 1465-72.

[11] N Kumar, B Tyagi and V Kumar. Multi-area deregulated automatic generation control scheme of power system using imperialist competitive algorithm based robust controller. IETE J. Res. 2017; 64, 528-37.

[12] N Kumar, V Kumar and B Tyagi. Multi area AGC scheme using imperialist competition algorithm in restructured power system. Appl. Soft Comput. 2016; 48, 160-8.

[13] N Kumar, B Tyagi and V Kumar. Deregulated multiarea AGC scheme using BBBC-FOPID controller. Arab. J. Sci. Eng. 2017; 42, 2641-9.

[14] A fathy and AM Kassem. Antlion optimizer-ANFIS load frequency control for multi-interconnected plants comprising photovoltaic and wind turbine. ISA Trans. 2019; 87, 282-96.

[15] S Prakash and SK Sinha. Load frequency control of multi-area power systems using neuro-fuzzy hybrid intelligent controllers. IETE J. Res. 2015; 61, 526-32.

[16] LA Zadeh. Fuzzy sets. Inform. Contr. 1956; 8, 338-53.

[17] EH Mamdani and S Assilian. An experiment in linguistic synthesis with a fuzzy logic controller. Int. J. Man-Mach. Stud. 1975; 7, 1-13.

[18] K Charles, N Urasaki, T Senjyu, ME Lotfy and L Liu. Robust load frequency control schemes in power system using optimized PID and model predictive controllers. Energies 2018; 11, 3070.

[19] M Ma, X Liu and C Zhang. LFC for multi-area interconnected power system concerning wind turbines based on DMPC. IET Gener. Transm. Distrib. 2017; 11, 2689-96.

[20] AS Mir and N Senroy. Adaptive model predictive control scheme for application of SMES for load frequency control. IEEE Trans. Power Syst. 2017. DOI: 10.1109/TPWRS.2017.2720751.

[21] PM Namara and F Milano. Model predictive control based AGC for multi-terminal HVDCconnected AC grids. IEEE Trans. Power Syst. 2019; 33, 1036-48. 